\title{
Developing multimodal communicative competence in emerging academic and professional genres
}

\author{
NOELIA RUIZ-MADRID \& JULIA VALEIRAS-JURADO \\ Universitat Jaume I (Spain) \\ Ghent University (Belgium)
}

Received: 30/10/2019. Accepted: 20/04/2020.

\begin{abstract}
In this paper, we propose a pedagogical approach for teaching and learning multimodal literacy, specifically, the application of multimodal discourse analysis for genre awareness. The mastery of specific oral genres is seen as desirable to help students become competent professionals. This is the case of Product Pitches (PPs) in the business field and Research Pitches (RPs) in the academic field. The former are short presentations that introduce a product to the market, the latter constitute an emerging way of disseminating ongoing research to the general public. A salient characteristic of both is their multimodal nature, which has raised an increasing interest in multimodal approaches to genre pedagogy. Our aim is to develop students' analytical skills to make them aware of the variety of semiotic modes and the importance of using them coherently. The pedagogical approach is facilitated by specialised software that supports the systematic teaching and learning of multimodal genres.
\end{abstract}

KEYWORDS: product pitches, research pitches, semiotic modes, genre awareness, multimodal literacy, genre pedagogy.

\section{MULTIMODAL APPROACHES TO PROFESSIONAL AND ACADEMIC GENRES}

The mastery of specific genres has become an integral part of the process to become a competent professional in many contexts, including business and academia. Both written and oral genres are indispensable tools that practitioners need to deploy skillfully in the development of their jobs. In particular, oral genres can present a challenge, especially when academics and professionals need to use English as a Lingua Franca, a situation which is

*Address for correspondence: Noelia Ruiz-Madrid \& Julia Valeiras-Jurado. Universitat Jaume I \& Ghent Univertity (Belgium); email: madrid@uji.es \& Julia.Valeiras.Jurado@ugent.be

(C) Servicio de Publicaciones. Universidad de Murcia. All rights reserved. IJES, vol. 20 (1), 2020, pp. 27-50 
nowadays widespread. This is the case of Product Pitches (PPs) in the business field and Research Pitches (RPs) in the academic field. The former are short presentations that introduce a new product to the market, the latter constitute an emerging way of disseminating ongoing research to the general public. Both are short, persuasive presentations in which speakers need to convince their audiences of the validity of a product or a piece of research, respectively. A salient characteristic of these presentations is their multimodal nature (Valeiras-Jurado, 2019; Ruiz-Madrid and Fortanet-Gómez, 2016). Speakers in these pitches resort to a variety of semiotic modes to convey meaning. Some of these modes are embodied, like intonation, gaze or gestures, and therefore they are largely unavoidable in any instance of oral discourse. Other modes are so widespread that they are generally taken for granted, like visuals in presentations. In any case, the success of oral professional and academic genres depends largely on a skillful orchestration of modes, in particular when speakers are not using their mother tongue (Morell, 2015).

Multimodal Discourse Analysis (henceforth MDA) offers a comprehensive approach for the fully understanding of the multimodal nature of genres. This approach has two important implications. On the one hand the study of discourse must broaden its scope to include non-verbal aspects. On the other hand, in order to fully comprehend any communicative process, every mode employed should be considered. Iedema (2003) summarises the main concerns of MDA in four main areas. First and foremost is acknowledging other semiotic modes apart from language. The second one is studying how the different semiotic modes work together in communication. Third is analysing how social changes affect the use of semiotic modes (e.g. technology can provoke a displacement of one semiotic mode by another). Finally, MDA also investigates how the potential of the different semiotic modes can influence interaction. Kress (2009), to a large extent in agreement with these four main concerns, states that there are four theoretical assumptions of multimodality: i) language is part of a multimodal ensemble; ii) each mode realises different communicative work: modes have been shaped through cultural, historical and social uses to realise social functions; iii) meaning is built selecting different modes and making them interact and iv) the meaning we interpret from semiotic resources is social; it is determined by our social context.

In the authors' view, a comprehensive MDA approach to genre study should include: i) the rhetorical dimension: the need to find and define the recurrent moves and explore the differences across genres and disciplines, ii) the multimodal dimension: the need to apply a method of analysis in which different semiotic modes are jointly analysed and iii) the pedagogical dimension: the need to design informed pedagogical proposals that help researchers, students and professionals effectively acquire the necessary generic.

In the following subsections, we will focus on each of these dimensions concerning the study of pitches. 


\subsection{The rhetorical dimension of pitches: the role of different semiotic modes in the rhetorical moves of the genre.}

Concerning the rhetorical dimension, many studies have approached the oral genre, in particular conference presentations (CP), from a multimodal perspective, proving that speakers fulfil their communicative aims through a combination of linguistic, paralinguistic and kinesic means. In particular, gestures, intonation and gaze serve as signposts to walk the audience through the presentation (Rendle-Short, 2006). These modes also contribute to achieve a desirable interpersonal relationship, showing (dis)engagement with the audience (Rendle-Short, 2006) and facilitating the expression of affect and evaluation (Hood \& Forey 2005; Querol-Julián \& Fortanet Gómez, 2012). A skillful use of modes can also make presentations more persuasive (Valeiras-Jurado, Ruiz-Madrid \& Jacobs, 2018). Although Research Pitches (henceforth RPs) can share many multimodal features with CPs, they differ significantly. They are probably one of the most recent oral genres in the academic field and are therefore less extensively studied. They are presentations which challenge young researchers to report their research in a limited time to a disciplinarily heterogeneous audience. Chang and Huang (2015) show that these presentations seek emotional and intellectual impact through the emphasis on a vocal and physical performance to connect with an audience. $\mathrm{Hu}$ and Liu (2018) focus on the rhetorical structure of research pitches and identify eight distinct rhetorical moves including six obligatory moves (i.e., Orientation, Rationale, Purpose, Methods, Implication, and Termination) and two optional ones (i.e., Framework and Results). To our knowledge, the only study approaching research pitches from a multimodal perspective is Ruiz-Madrid and Fortanet-Gómez (2016), in which the multimodal nature of this genre is brought to the fore and related to its rhetorical structure, with a focus on the opening and closing moves.

In the case of Product Pitches (henceforth PPs), research has proved that modes like gestures or intonation have a remarkable effect on the audience. Huang and Pierce (2015) show that nonverbal cues (e.g. gestures) highly influence investor's decisions. Similar results were obtained by Clarke, Cornelissen and Healey (2019). They proved that gestures have a significant influence on the propensity to invest, specially ideational gestures that depict the product or service and trigger mental imagery. Niebuhr, Voße and Brem (2016) analyse the use of prosodic features in Steve Jobs' product presentations and they reveal certain characteristics that contribute to project a charismatic figure, such as a relatively high pitch for a male voice and a faster pace than usual in public speaking. Cestero-Mancera (2017, 2018) have published two of the few studies approaching product pitches from a multimodal perspective taking into account a wide range of modes. Non-verbal modes are found to be abundant in product pitches, and they perform the following functions: get the attention of the audience, regulate communication, facilitate understanding of the message and express emotions, motivations and attitudes. 
In view of the multimodal nature of both emergent genres, RPs and PPs, an efficient use of modes is a must for professionals who need to master these genres. In this paper we present a pedagogical proposal to help students achieve this goal.

\subsection{The multimodal dimension of pitches}

Two multimodal studies of RPs and PPs informed the pilot study described in this paper. They are discussed in the following paragraphs.

Ruiz-Madrid and Fortanet-Gómez (2016) focused on Research Pitches and with the help of the annotation software ELAN ${ }^{1}$ for the multimodal analysis of the corpus, they unveiled the rhetorical structure of a corpus of Research Pitches and its relation with the multimodal ensembles used in the opening and closing moves, as shown in Figure 1:

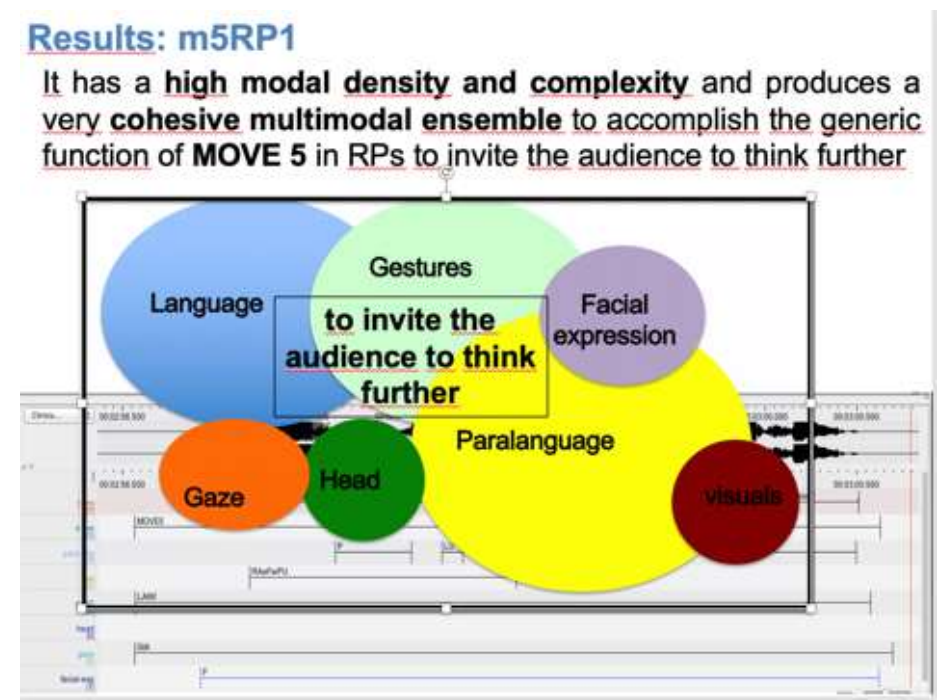

Figure 1. Multimodal ensemble resulted from the MDA

Of the closing move in RP1.

Multimodal ensembles refer to the orchestration of different modes to produce a specific meaning that is inferred based on the interrelation among them. Accordingly, Figure 1 represents the multimodal ensemble using bubbles with different colours and sizes. Each colour represents one mode, and the size of the bubble represents the intensity with which the mode is being used, or in other words, its relevance within the multimodal ensemble. The communicator orchestrates multimodal ensembles, where each mode has a function (Kress, 2010) and "each mode is partial in relation to the whole meaning" (Jewitt \& Kress, 2003: 3). Lemke (1998) refers to this phenomenon as the multiplying effect.

In Valeiras-Jurado (2019), a comparative analysis of a PP and a research TED talk reveals that both presentations use a variety of modes that interrelate in different ways creating complex multimodal ensembles. The intensity and the complexity of these interrelationships is what Norris (2004) calls modal density In addition, the comparative 
analysis shows the importance of combining these modes in a coherent way to create a persuasive presentation. Figure 2 shows the multimodal ensemble identified in the PP. The size of each balloon represents how much each mode is used. The text inside each balloon indicates the persuasive strategies that each mode is contributing to. As it can be seen, there is an unbalanced predominance of words (bottom left), which makes the ensemble less coherent, and the presentation less effective.

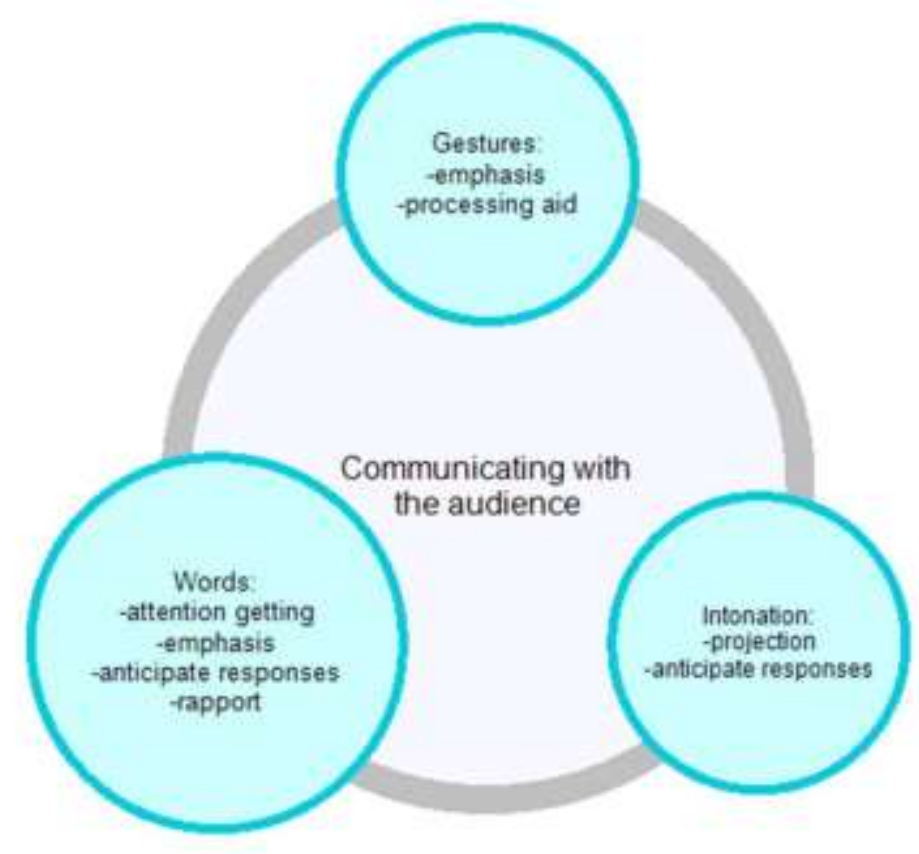

Figure 2. Multimodal ensemble resulted from the MDA of a PP.

In the studies described in the previous paragraphs efficiency is understood as largely equivalent to persuasiveness, given the strong persuasive component in both genres - their aim is to convince of the validity of a product (PP) or a piece of research (RP). Likewise, in both studies emphasis is laid in the multimodal ensemble as a whole rather on the individual contribution of each semiotic mode.

As already mentioned, for both analyses we employed the software ELAN to annotate the extracts and organize these annotations in hierarchical layers that are time-aligned. This feature is crucial since it allows us to look at the synchronicity of modes and focus on the multimodal ensemble being used at any given moment. However, this programme presents limited capabilities for quantitative analysis and visual representations. For this reason, in more recent analyses (publications forthcoming) we have turned to the software, MMAV ${ }^{2}$. This programme uses quantitative data to automatically produce a visual representation of the ensemble (how much and when each mode is used), which enables us to base our visual 
representations on accurate data rather than on more subjective perceptions. Figures 3 and 4 illustrate this difference between programmes.

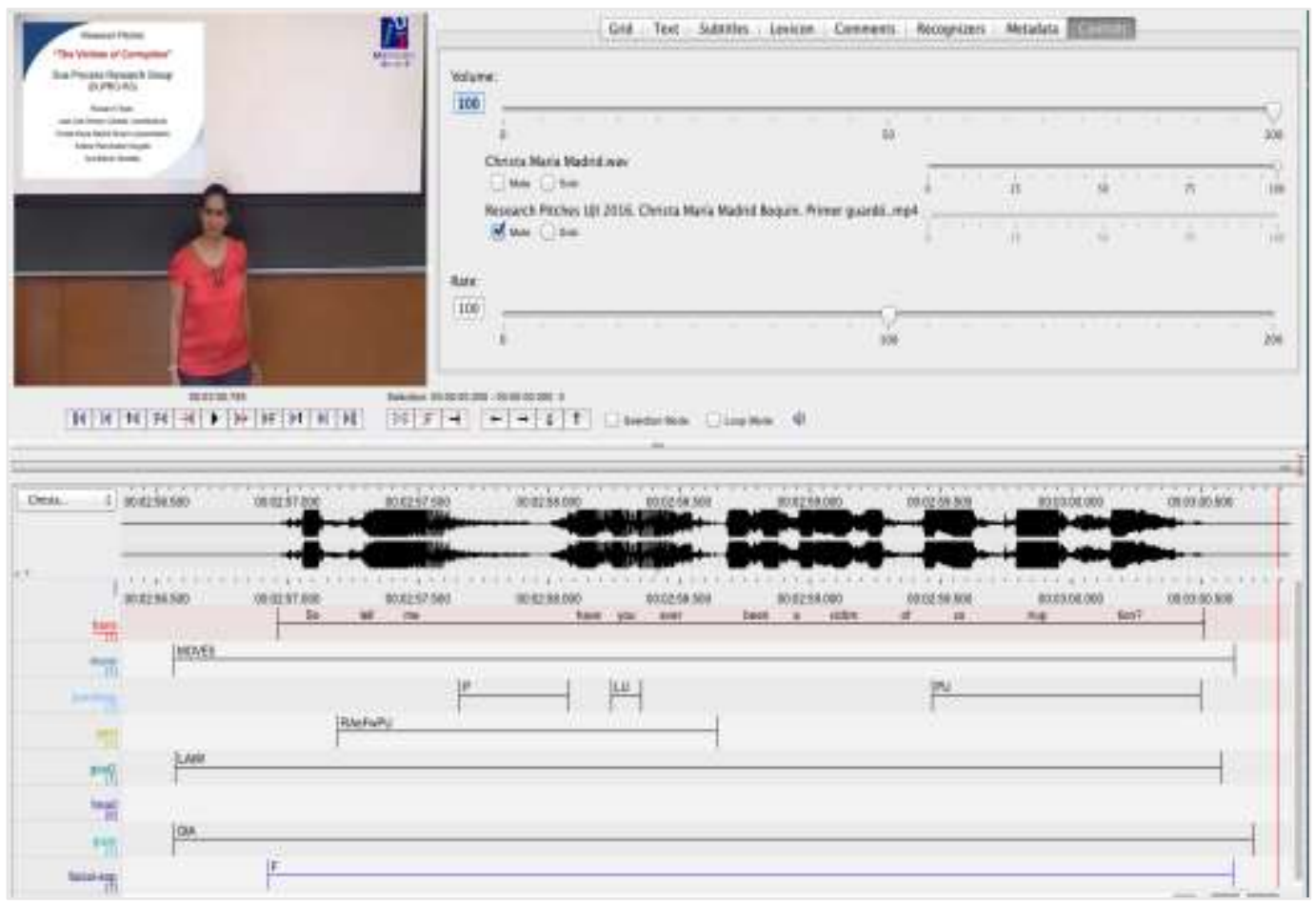

Figure 3. Elan software-mediated analysis of a Research Pitch.

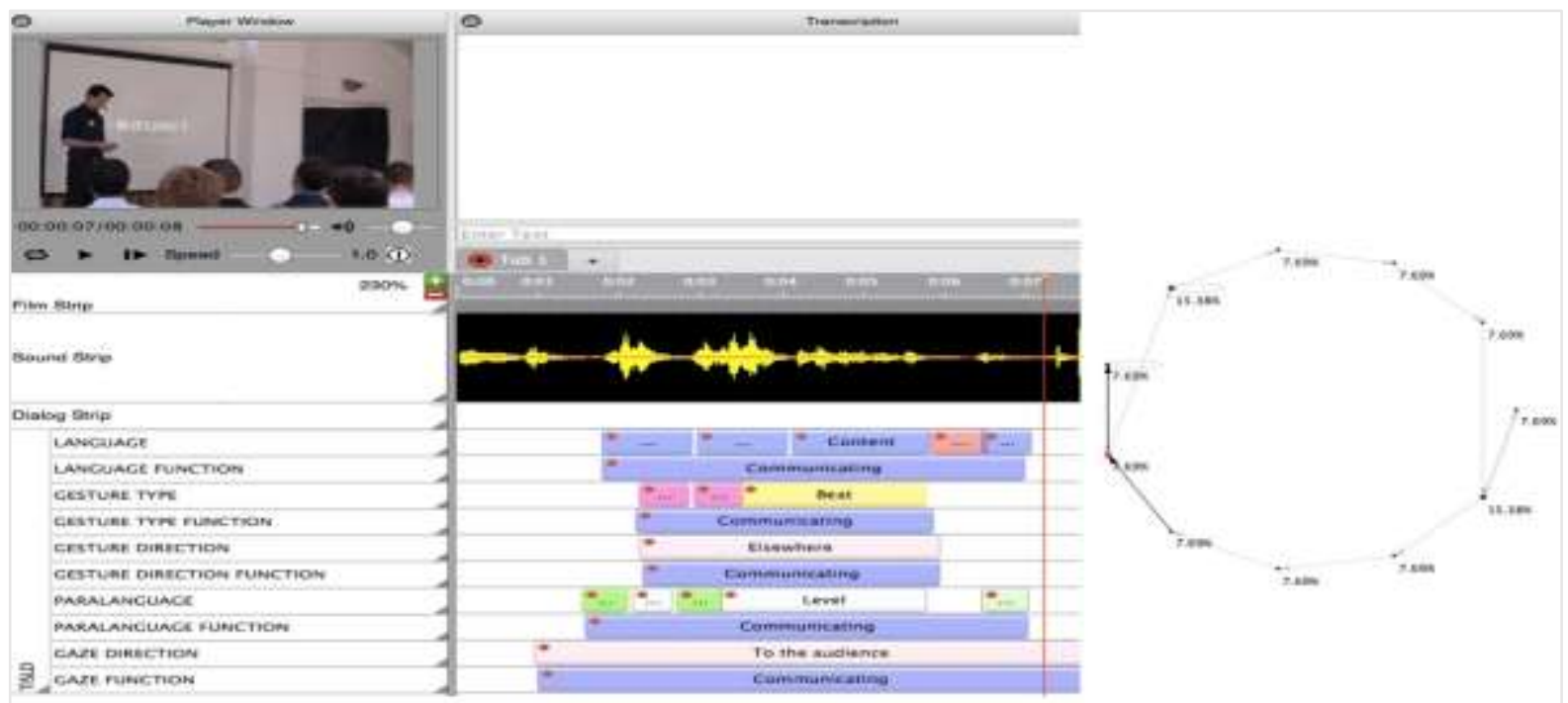

Figure 4. MMVA software-mediated analysis of a Product Pitch.

\subsection{The pedagogical dimension of pitches}

The strong multimodal character of academic and professional genres has recently raised an increasing interest in multimodal approaches to genre pedagogy (Busà, 2010; CampoyCubillo \& Querol-Julián, 2015; Crawford-Camiciottoli \& Campoy-Cubillo, 2018; Fortanet- 
Gómez \& Bernad-Mechó, 2019; Jiménez-Muñoz, 2019; Morell, 2015, 2018; O'Halloran et al 2015, 2016; Palmer-Silveira, 2015; Querol-Julián \& Fortanet-Gómez, 2019; Ruiz-Madrid \& Fortanet-Gómez, 2019), and to language learning in general. The New London Group (1996), for example, support the idea that students need to develop a broader set of literacies to be able to master the multiple modes of meaning making. They further claim that a metalanguage is needed to achieve this aim, a view that is shared by Forey and Feng (2016) and Cocetta (2018). Stein (2000) is also in favour of multimodal pedagogies and believes that language teachers should focus on "tasks or projects for students that require multiple forms of representation, of which language is only one part" (Stein, 2000: 335). Similarly, Ajayi (2009) claims that:

multimodal/multiliteracies pedagogy has the potential to provide opportunities for ESL students to learn about different text types in ways that enhance the expansion of interpretation of texts. Multimodal pedagogy goes beyond language to promote alternative ways of reading, interpreting and text composing. (p. 587)

Cocetta (2018) shows the positive effect of guided multimodal discourse analysis activities in students' awareness of the integration of different semiotic modes. In her study students also developed a metalanguage to talk about texts and were better able to relate the text under analysis with its context of situation and culture. Similarly, Jiménez-Muñoz (2019: 83) claims for an improved method of assessment for multimodal pedagogy in ESP contexts "one that includes both speech and other modalities, including task effectiveness under simulation, to better match the real-life skills targeted by curricular design".

The teaching and learning of multimodal competence in oral genres in general, and in oral emergent genres in particular, is a crucial component of the curriculum in ESP and EAP courses. At the same time, and despite the great advances in digital tools, it still poses a great challenge for teachers and students alike. The main reasons behind this are the following: 1) there is a lack of appropriate metalanguage, and 2) there is still a huge gap between what Airey (2016) calls the disciplinary affordance and the pedagogical affordance. That is, the more disciplinary valid an instantiation of a genre from the point of view of the insiders (i.e. discipline experts), the more complex this example will be and therefore the less useful for pedagogical purposes. For instance, a long and complex equation can be considered a valid and effective disciplinary affordance for discipline experts. Yet, the disciplinary affordance loses its effectiveness when explained to students or non-experts, since teachers have to transform the disciplinary affordance to a pedagogical one to be able to communicate the discipline.

As language teachers of ESP and EAP, we need to help students develop multimodal communicative competence and multimodal literacy of genres that are widely used in their respective areas. But in order to do that, and in addition to an appropriate metalanguage, we need to bridge the gap between discipline and pedagogy. The benefits would include a more 
realistic and therefore effective approach to multimodal competence applied to genre pedagogy. The learning of the multimodal communicative processes and semiotic resources used to transmit the targeted disciplinary knowledge should be explicitly taught and considered important in the assessment of the task along with the task outcome itself, in light of their impact on the communication process.

Digital tools can definitely be of great help in this task. The potential of tools like ELAN that allows for a hierarchical framework for analysis in different tiers which can be time aligned, and the more recent MMAV which in addition provides visual representations of quantitative data, is not to be underestimated. It is precisely this visual representation that we believe is of particular use in the classroom, because it can be a very powerful tool to draw attention to modes that are not so consciously used. In fact, this has been proved to be the case with intonation: Hincks $(2005 ; 2009)$ suggests that the use of computer-assisted visual automated feedback can help students improve their use of intonation in presentations. We hypothesize that visual representations of the use of other modes will help students to use them more consciously and eventually more effectively.

However, using this software in the classroom to analyse and fully comprehend the relevance of multimodality in oral genres could not be pedagogically relevant because of several reasons: the analysis is time -consuming, and above all the interpretation of results can be difficult, to the point that students might feel lost when exposed to the complexity of the multimodal communicative process. In the specific context of teaching oral genres, the more disciplinary appropriate an instantiation of a genre, the more complex its multimodal analysis will turn out to be, and therefore the less appropriate for pedagogical purposes. Students should be able to make sense of the different semiotic resources that they have available, but at the same time they have to be aware that semiotic modes do not work separately. Instead they should learn that each mode adds up to become a more comprehensive construct than the sum of its parts, and that all modes contribute in different, but equally important ways, to achieve the communicative aim of the genre. An appropriate metalanguage and a pedagogically affordable multimodal approach are needed to achieve these goals.

The aim of this study is to try to reach a compromise between the complexity of computer assisted multimodal analysis and the pedagogical applications of this analysis for non linguists. In particular, we use visual representation of the use of modes in different oral genres to raise multimodal awareness and foster multimodal literacy among students. This will ultimately help them use these emergent genres more efficiently. In the subsequent sections we present a pilot study involving ESP students learning the principles of effective product pitches and research pitches. 


\section{METHOD}

\subsection{Participants and context}

The participants in this study were 36 second-year Dutch-speaking undergraduate students enrolled in the degree of Economics at Ghent University in Belgium. Their English proficiency was estimated to be a B2/C1 since at the end of high-school these students are expected to reach a B2 level of English as established by the Common European Framework of Reference for Languages (CEFR). All the students were engaged in the subject Economic English. This subject is three ECTS and takes place once a week for 90 minutes each session during the whole academic year. The main aim of this subject is to provide students with "more advanced communicative skills in a general economic and business context", being one of the final competences included in the syllabus "to be able to do longer presentations and take part in more complex oral interactions in English"3.

\subsection{Method and materials}

In order to develop our pedagogical proposal, we employed one session of $90^{\prime}$ in the $2^{\text {nd }}$ semester, since students were then preparing their oral assignments. Students are required to do two oral assignments as part of the subject assessment. First, they prepare a 30' workshop in teams of $4 / 5$, and they deliver it to their classmates. The topic of this workshop has to be related to the class material, but the exact content is decided by the students themselves. They are encouraged to do research on this topic and they are prompted to present it in an interactive way, including activities involving the rest of their classmates. Secondly, they do an individual oral exam in which they have to expand on two of the topics dealt with in class for 10 minutes. The main aim is to prompt critical discussion of the topics rather than a mere recollection of the content. Because of this, students are encouraged to structure their answers coherently and produce convincing arguments to support a concise but consistent critical discussion. In both tasks students are asked to be communicatively effective and sound convincing, which implies a coherent use of different semiotic modes.

The activity designed for the purpose of the present study was introduced to students as a preparation for these oral tasks (see Appendix). Students were informed that the main aim of the activity was making them pay attention to the use and effect of multimodal resources when delivering an oral presentation. The activity consisted of 5 exercises aimed at developing students' awareness of the use of semiotic modes. In order to do that we videoplayed three different examples of pitches: two closings of product pitches (one more persuasive and one less persuasive) and the opening of a winning research pitch.

We selected these two different types of pitches mainly for two reasons: firstly, although different in field-content (i.e., business and research), we considered that both types of pitches were complementary and effective for the final aim of the task designed, that is helping students prepare their oral assignments and being aware of the communicative role of 
the semiotic modes when attempting to be persuasive. Accordingly, students must do some research to deliver a workshop on a specific business topic and then answer the exam questions in a structured and convincing fashion. Therefore, we think that introducing two different models (i.e., one more academic and the other one more business-topic centered) might provide students with more varied and meaningful examples that could help to raise their multimodal awareness and eventually encourage them to employ different semiotic modes in their workshops and oral exam. On the other hand, these three examples had already been analysed from a MDA approach by the authors (see Section 2), and results from previous software-based analyses could be implemented in the activities.

Following Hincks (2005; 2009), who suggests that the use of computer-assisted visual automated feedback can help students improve their use of intonation in presentations, we hypothesized that the same could be extended to other modes like gestures. Yet, it is important to note that the software itself is not used in the class in the present study, since the complexity of the analysis would make it not apt for pedagogical purposes. However, the analysis of the modal ensemble that this software facilitates and its visual representation can be used for pedagogical purposes, as we will clarify in the following paragraphs.

The final aim of the five activities included in the task (see Appendix) was twofold. On the one hand, we aimed at fostering students' multimodal communicative competence, which allows them to cope with multiple modes of meaning making (i.e., multiple semiotic modes) (Cocetta, 2018; The New London Group, 1996). On the other hand, we tried to construct a common framework between teachers and students that would allow sharing a common metalanguage for talking about language, images, texts and meaning interactions in multimodal texts and relate these to the contexts of culture and situation in which they seem to work (New London Group, 1996: 77) in order to foster an effective pedagogy of multimodal communicative competence.

In activity 1 students were asked to watch two examples of product pitches and rate them according to persuasiveness on a scale from 1 to 20 , since it is the scale employed in the grading of their assignments and therefore students were expected to be familiarised with it. They were also asked to justify their ratings (see Activity 1 in Appendix). In both examples the extracts shown in class corresponded to the closing move. This is considered one of the most persuasive moves in the rhetorical structure of product pitches, as presenters should make a last effort to convince their audience about the strengths of the product they present (Valeiras-Jurado, 2019; Cestero- Mancera, 2018). Both pitches were recorded at a product pitch contest organised in cooperation between the University and the Flemish government. Example 1 lasted 08''08 and presented a waxing kit for sky equipment. Example 2 had a duration of 08 ' 05 and introduced a social media app. Both extracts (i.e., closing moves) were selected by researchers on the basis of their multimodal nature. In the case of Example 1 , previous analysis revealed a high modal density extract in which the presenter makes an 
effective use of semiotic modes in order to transmit a persuasive message to the audience. Example 2, on the other hand, was a low modal density extract and semiotic modes were scarcely and incoherently employed by the presenter (Valeiras-Jurado, 2019). The final aim of this activity was making students aware of the effect of the use of semiotic modes when trying to persuade an audience, by showing them two opposite examples in terms of multimodal nature.

In Activity 2 students were asked to provide some quantification of the use of modes by watching the videos shown in Activity 1 and noting whether some specific semiotic modes (i.e., language, gesture, intonation and gaze) were used by presenters and if so, to what extent (i.e., from 0-20, being 0 never and 20 always) (see Activity 2 in Appendix). The multimodal ensembles included in the activity had been previously analysed by researchers (ValeirasJurado \& Ruiz-Madrid, 2019; Valeiras-Jurado 2019; Ruiz-Madrid and Fortanet-Gómez, 2016). These analyses took into account the following semiotic modes:

a) words, mainly those used as stylistic strategies and metadiscourse (Fuertes- Olivera et al., 2001; Hyland, 2005);

b) four types of kinesics and the way they interact with the speech: gestures, head movement, facial expression (Kendon, 2004), and gaze (Argyle et al., 1981);

c) paralanguage as well as the functions it accomplishes in the discourse (Brazil, 1997; Poyatos, 2002); and

d) the visual material used by the speakers.

However, for the purpose of the study, the number of modes was reduced. Likewise, the academic terminology to define these modes was simplified and examples were given to students. Indeed, only words, gestures, gaze and intonation were considered for the activity and described to students in a more simple way: words were said to be the language used by the speaker, gestures were introduced as 'any type' of relevant and significant gesture made by the speaker, gaze was considered as the direction and intensity of presenters' gaze while presenting. Finally, instead of using the term paralanguage, we employed the term intonation which can be more recognisable by the students doing the activity. It is necessary to point out here that participants were not linguists nor students of linguistics, but students enrolled in a Degree of Economics. A more complex task involving more modes could have hindered the task development and resulted in a more cognitive overloaded activity.

Activity 3 pivoted on the visual representation of the multimodal ensembles of the extracts shown in Activity 1 and 2 (see Activity 3 in Appendix). Students were asked to match each extract with its correct multimodal ensemble. Researchers retrieved the visual representations of the multimodal ensembles from previous MDA of the product pitches employed in the task here described (Valeiras-Jurado, 2019). The pedagogical aim of this activity was to provide students with a model to represent and eventually interpret the nature of multimodal ensembles as part of the multimodal literacy involved in oral academic discourse. Our intention was to show them that each mode adds up in a multimodal ensemble 
to become a whole communicative construct and that all modes contribute in different, but equally important ways, to achieve the communicative aim of the genre.

Activity 4 was aimed at making students reflect on all the aspects previously worked on in Activities 1, 2 and 3. In order to make them be actively engaged in the activity, researchers introduced a different extract. In this case, the opening move from a Research Pitch was used, offering students a new context to analyse (i.e., academic discourse and an opening move) (see Activity 4 in Appendix). Students were asked whether they found the extract persuasive. Accordingly, students had to answer YES/NO and give reasons for their answer. Finally, in Activity 5, students were asked to draw the visual representation of the multimodal ensemble of this extract (see Activity 5 in Appendix).

\section{RESULTS AND DISCUSSION}

In this paper, we present a pedagogical proposal aimed at bridging the gap between the MDA research and genre pedagogy. For the purpose of the present study, we focus on two particular genres: product and research pitches and in the teachability of the multimodal nature of their communicative aim. The analysis of results shows that pedagogical proposals like the one here described might raise students' awareness on the multimodal nature of these particular genres and its communicative effectiveness. In this sense, results obtained from Activity 1 reveal that students perceived Example 1 (i.e., the more multimodally dense and effective according to our previous analyses) as the most persuasive of the two examples. Students rated Example 1 (i.e., 11.45/20) higher than Example 2 (i.e., 9.57/20). The ratings were done on a scale over 20 because it is the system normally used at the university and the one they are more familiar with. Although the difference was only of 1.88 , which might not be considered as significant, students' justifications indicate that they perceive Example 1 as more persuasive than Example 2. In this sense, students' comments refer to two different aspects: presenters' attitude/behaviour and presenters' use of semiotic resources. Concerning the presenter's attitude/behaviour in Example 1 students employ expressions such as "more confident" or "good posture." Concerning his use of multimodal resources, students referred to "good use of gestures," "he uses his hands a lot," "intonation is very expressive," among others. Regarding Example 2, students describe the presenter's attitude/behaviour using terms with more negative connotations such as "he stands back to the audience," "he doesn't look very enthusiastic" or "at some points it is difficult to understand." As for multimodal resources, students did not make any significant reference to any of the modes. This leads us to think that students might have perceived this presenter's use of modes as largely irrelevant in his discourse. Figure 5 summarises the results ${ }^{4}$ of Activity 1: 


\begin{tabular}{|c|c|c|}
\hline & EXAMPLE 1 & EXAMPLE 2 \\
\hline $\begin{array}{l}\text { Students' } \\
\text { average } \\
\text { rating }\end{array}$ & $11.45 / 20$ & $9.57 / 20$ \\
\hline $\begin{array}{l}\text { Summary } \\
\text { of students' } \\
\text { comments }\end{array}$ & & \\
\hline
\end{tabular}

Figure 5. Summary of results in Activity 1.

Activity 2 asked students to look more closely into the use of modes in both extracts by quantifying them in relative terms. Students had to rate the frequency of use of each mode by using a three- level scale: a lot, average and little. As mentioned before, researchers tried to apply a simple methodological design to the activity in order to keep students focused on the what and not on the how. As shown in Figures 6 and 7, students' responses reveal a clear difference in the way they perceive the use of semiotic modes in Example 1 and Example 2.

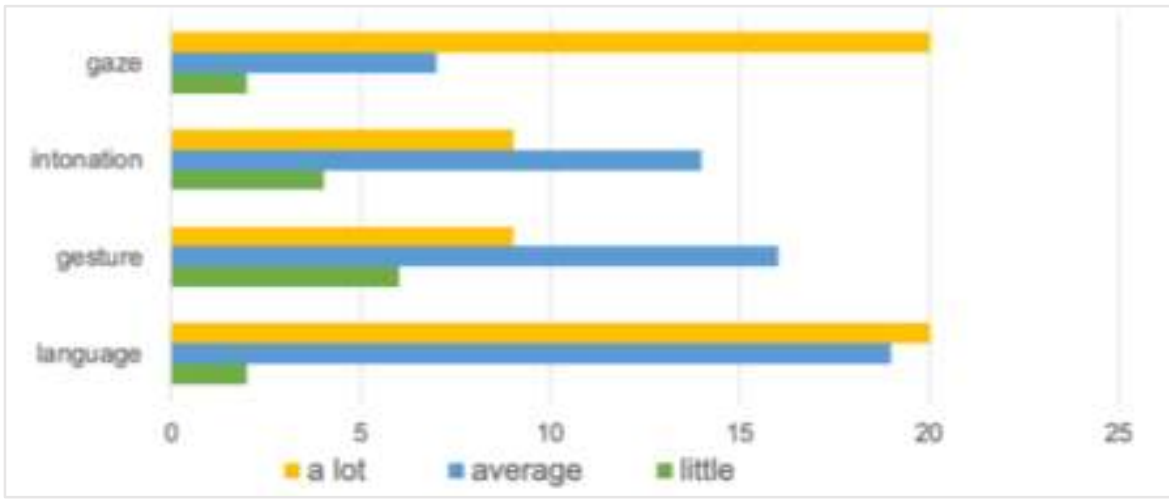

Figure 6. Students' perception on the use of semiotic modes in Example 1.

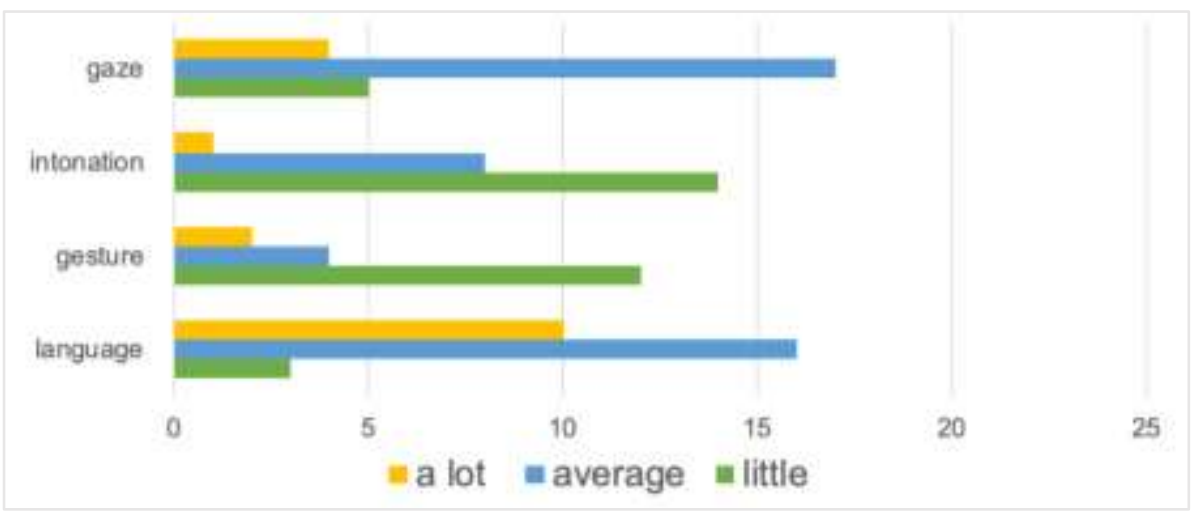

Figure 7. Students' perception on the use of semiotic modes in Example 2.

As might be expected in line with the results obtained in Activity 1, students considered that semiotic modes were used at a higher rate (i.e., a lot or average) in Example 1 and less in Example 2, where little and average are the most common answers. Having a 
closer look at the results in Extract 1, students pointed out gaze and language as the most extensively used modes, while intonation was the least significant for them. In Example 1, language is also considered the most important semiotic mode. In both cases, however, the lowest-rated semiotic modes are intonation and gestures. In the case of intonation, the students' profile might be considered, since the effect of intonation on L2 discourse can be difficult to understand for business students. Research tells us that the difficulties in the learning of L2 intonation patterns are often due to the non-equivalence of the intonation structure of the learners' L1 and the L2 structure (Anderson-Hsieh \& Koehler, 1988). As for gestures, students' lack of training on the meaning and effect of gestures, together with a traditional view to focus on language especially in language learning courses, might hinder their analytic perception. However, as seen in Figure 2, results from a previous MDA of Example 2 revealed that the use of gestures was not significant in the construction of the communicative aim of this excerpt. Indeed, the MDA of Example 2 revealed a lower multimodal density in comparison to Example 1.

The goal of activity 3 was to familiarise students with the visual representation of multimodal ensembles and therefore provide them with a comprehensive understanding of how the different semiotic modes can interact in order to convey a meaningful communicative aim. This is our way of bridging the disciplinary and pedagogical knowledge by bringing a complex scientific analysis closer to the students (Airey, 2016). Additionally, the way each mode is represented adds extra meaning to the construct itself. As explained in section 2, each mode is represented in a bubble, and the size of each bubble representing a specific mode varies depending on its frequency during the extract. Accordingly, two different visual representations of multimodal ensembles were included in the activity. Number 1 was the multimodal ensemble of Example 1 and number 2 corresponded to the multimodal ensemble of Example 2. Results showed that most of the students (33 out of 36) matched each of the visual representations of the multimodal ensemble with the correct extract. Although the activity was not complex in terms of performance, the conceptual complexity inherent to the comprehensive understanding of the visual representation makes us think that this activity could be considered an effective model for multimodal communication teaching in L2 contexts. This result is line with previous studies on teaching complex discourse elements through visualization techniques (Bonsignori, 2018, 2019; Levis and Pickering, 2004). 


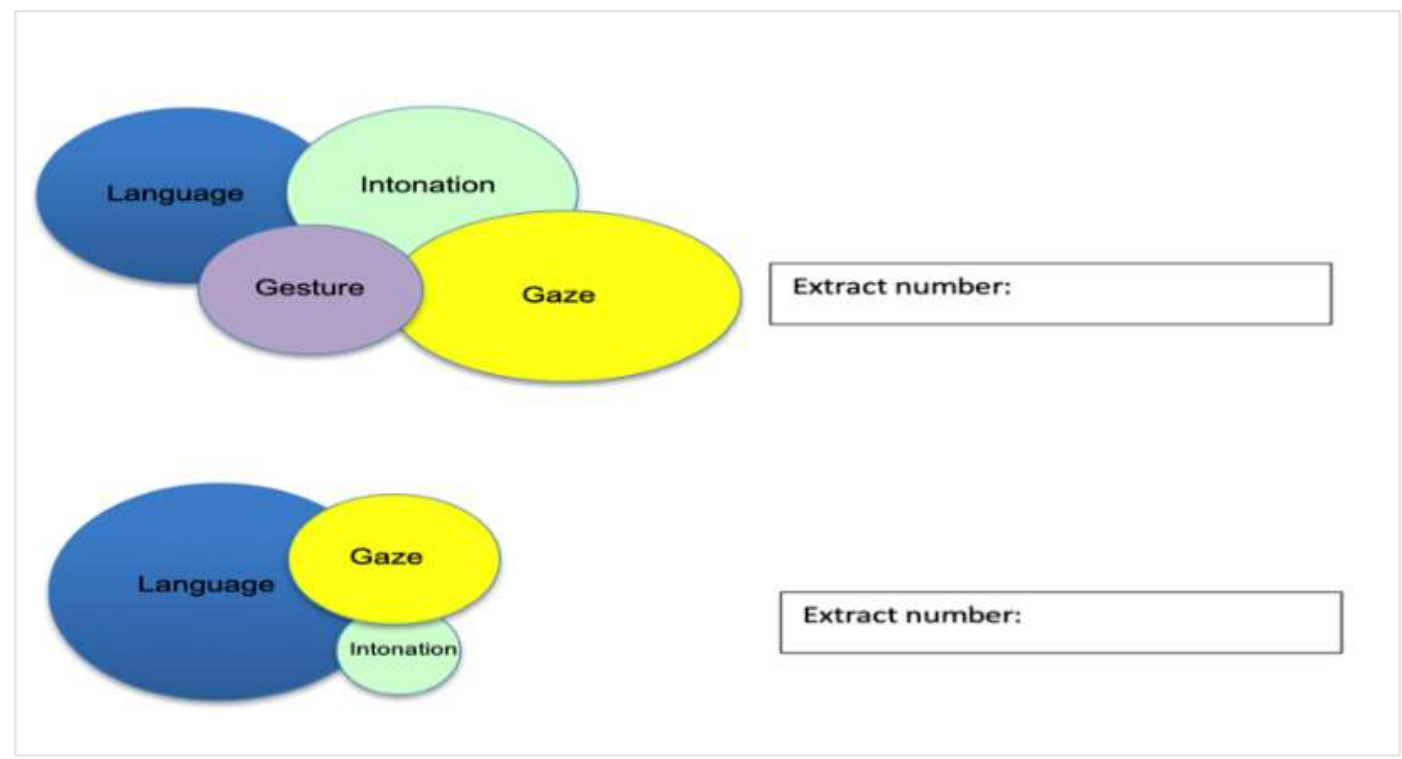

Figure 8. Visual representation of multimodal ensembles of Extract 1 and 2.

Activity 4 presented a new Example (i.e., Example 3) taken from the research pitch, in which the presenter introduces her research on corruption (Ruiz-Madrid and FortanetGómez, 2016). In this case, students were asked to put into practice all the aspects already seen in the previous activities (i.e., efficiency in delivering the message, identification of different semiotic modes and visualization of a specific multimodal ensemble). Results from the first question showed that $92 \%$ of the students considered the speaker to be effective (i.e. persuasive) in delivering the take-home message (i.e., Figure 9). In this example the speaker resorts to a varied number of semiotic modes that result in an effective communicative multimodal ensemble. As the results from this first question show, most of the students recognize this effectiveness when delivering the take-home message.

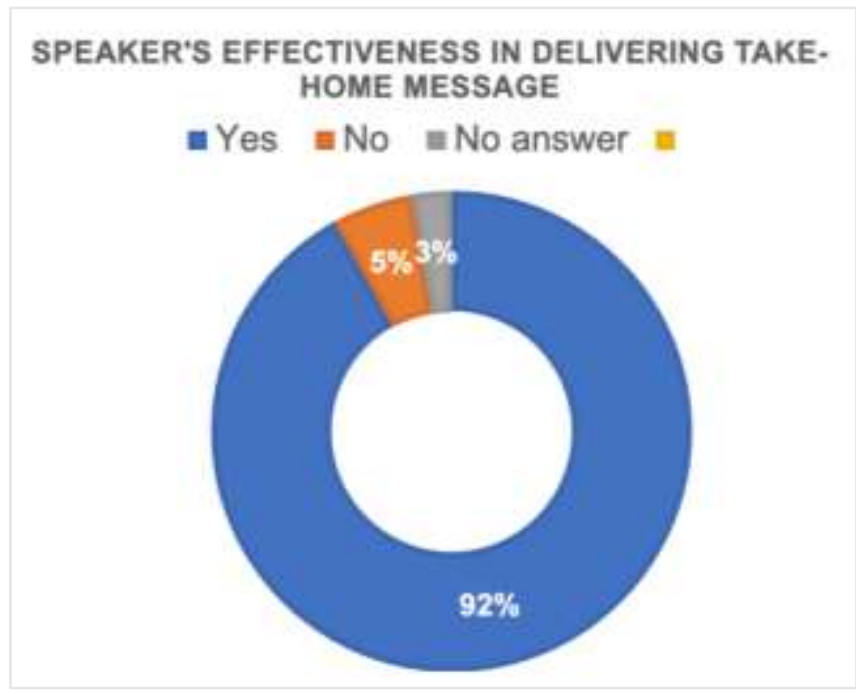

Figure 9. Results for Activity 4.

This result is confirmed when analysing students' justification of their answer to the first question. As it can be seen in Figure 10 students again refer to the presenter's attitude 
and her use of semiotic modes with expressions like "she is confident, uses hand gestures and has great intonation ${ }^{5 \%}$. In fact, self- confident and effective use of multimodal resources are the most recurrent aspects mentioned. Aspects that were also present in the results of the MDA conducted by researchers (Valeiras-Jurado, 2019; Ruiz-Madrid and Fortanet-Gómez, 2016).

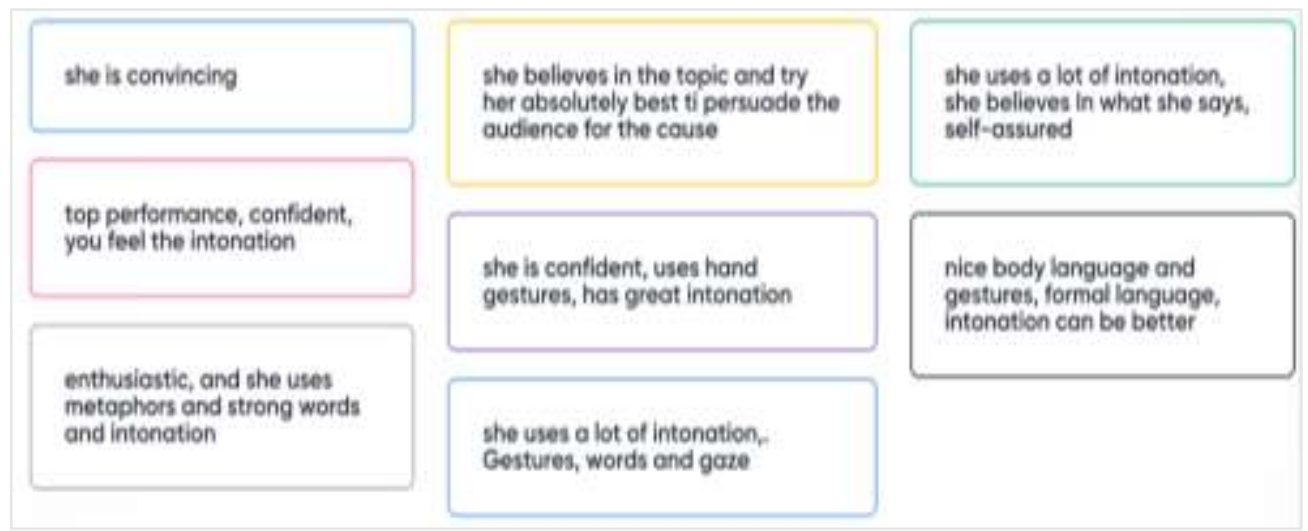

Figure 10. Students' justification in Activity 4.

In Activity 5 students were asked to draw the multimodal ensemble that resulted from Extract 3. In order to do that, researchers reminded students to look at Activity 3 as a model and size each semiotic mode according to its frequency of use in the given Example. Figure 11 shows one of the multimodal ensembles drawn by a student:

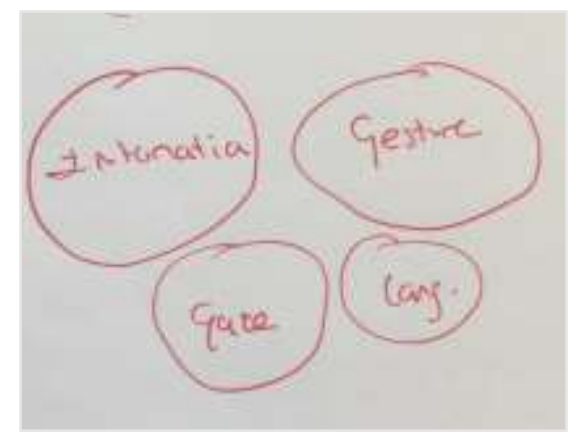

Figure 11. Student's 1 visual representation of the multimodal ensemble of Example 3.

In order to obtain the average multimodal ensemble of all the students' visual representations, researchers rated each bubble size with a value from 1 to 4 , being 1 the biggest and 4 the smallest bubble. Then, all number $1 \mathrm{~s}, 2 \mathrm{~s}, 3 \mathrm{~s}$ and $4 \mathrm{~s}$ were quantified and final results considered for the representation of the average multimodal ensemble as shown in Figure 12: 


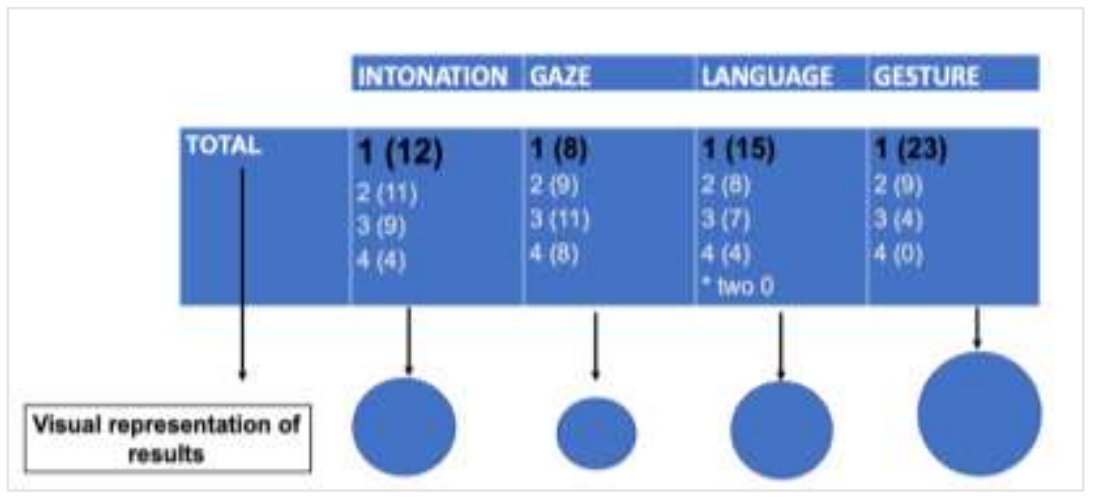

Figure 12. Process of data gathering in Activity 5.

As shown in Figure 13, the visual representation of the multimodal ensemble of Example 3 resulting from students' answers in Activity 5 is very similar to the one obtained by researchers in the previous multimodal discourse analysis.

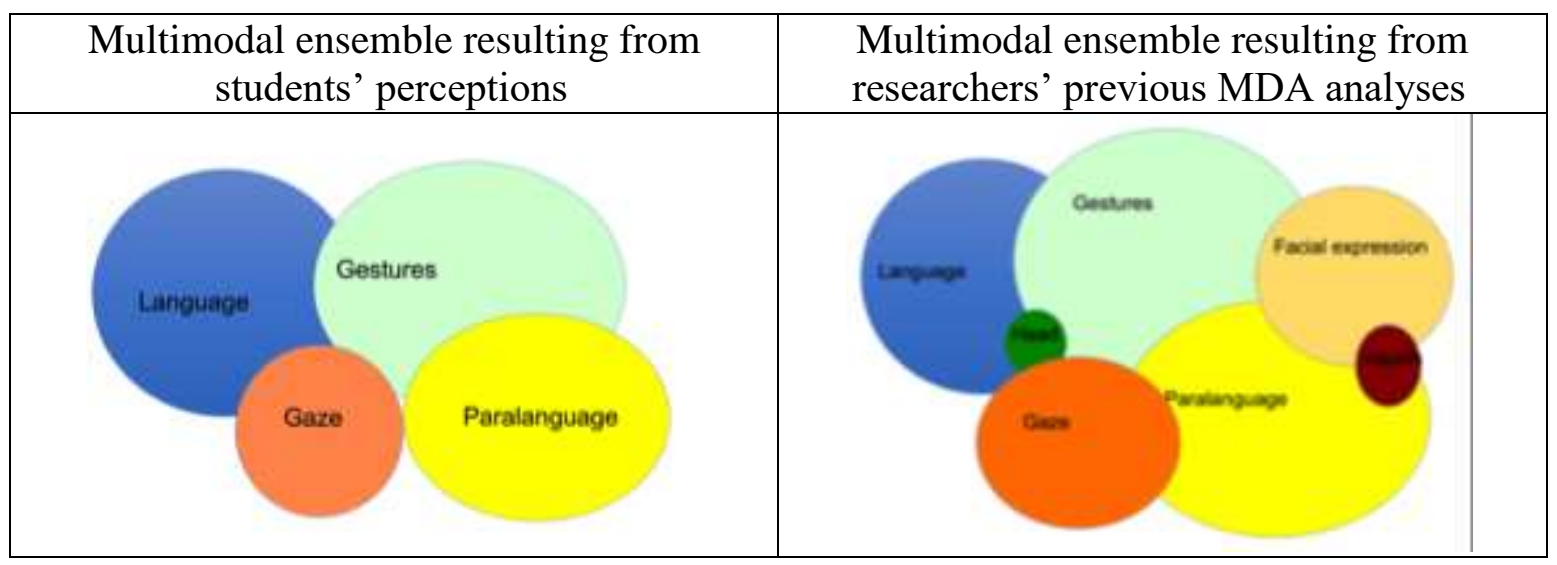

Figure 13. Comparison between both visual representations of multimodal ensembles.

As it can be seen in Figure 13 the only difference between both multimodal representations is the presence of more modes in the researchers' ensembles, since, as already explained, we decided to simplify and reduce the number of modes to be analysed by students. Another interesting aspect is that, although researchers decided to use the term intonation instead of paralanguage, the students' answers show that they were considering intonation as something broader, since they mentioned in this category aspects such as silence. For this reason, researchers considered to rename the 'intonation' bubble as 'paralanguage' in the final representation. This result shows that students were able to identify, interpret and represent a correct multimodal ensemble as well as its communicative intention as seen in their comments in Activity 4. Students were able to understand and reproduce the pedagogical affordance in order to unveil the disciplinary communicative affordance contained in the multimodal ensemble of Extract 3 (Airey, 2016; Ruiz-Madrid and Fortanet-Gómez, 2019). 


\section{CONCLUSIONS AND PEDAGOGICAL IMPLICATIONS}

The pilot study presented in this article has provided a pedagogical proposal on how research into MDA can be integrated into an ESP university syllabus for Business English to foster students' multimodal communicative competence awareness of oral academic genres, being the case, product and research pitches. The added value of this MDA approach is the use of real corpora for researching and teaching proposes and its transferability to all modes, genres and disciplines. In addition, multimodal corpus-based training proposals for students and teachers should aim at raising awareness and encouraging reflection on the balanced and coherent use of the different modes involved in oral academic communication. In order to do that, software packages such as ELAN or MMAV could inform class activities and be employed both as an analysis tool and as a feedback tool. This will afford studies and practices that will provide for sure new insights into multimodal and digital literacy.

This pilot study presents some limitations concerning methodological aspects. First, the study is limited to a 90' task. A longer-term task or different tasks throughout the course year could help researchers to validate the results obtained. In this sense, a more complex pedagogical proposal about students' recognition of gestures and intonation might be necessary. Results from our study reveal that students easily identify gaze or words, while they have difficulties in identifying gestures or intonation. This might be due to lack of training on these particular semiotic modes. Yet, further research might help to explore this aspect in detail. Another aspect to take into account concerning limitations might be the evaluation of the students' evolution on multimodal awareness. It was subjective and based only on their responses to the task proposed due to a lack of a specific assessment rubric for multimodal communicative competence to be applied. In our opinion, this is not sufficient to establish the exact extent of the students' proficiency in multimodal proficiency. Following Querol-Julián and Campoy-Cubillo (2015), Coccetta (2018) and Jiménez (2019), further research might be focused on a comprehensive and objective definition of the descriptors considered in multimodal communicative competence. One model to follow could be the description of Mediation competence included in the new CEFR (Council of Europe, 2018), which has been considered as part of the communication modes necessary for a language learner to be communicative proficient in a L2. Likewise, the design of a multimodal competence scale with clear evidence of learning objectives, as in the case of the mediation competence, would provide a comprehensive formative assessment for the teaching and learning of the multimodal communicative procedures and devices used to transmit the targeted disciplinary knowledge or accomplish the disciplinary task. This may be useful for those ESP/EAP lecturers willing to include multimodal aspects in light of their impact on the disciplinary communication. 


\section{NOTES}

${ }^{1}$ Available at https://tla.mpi.nl/tools/tla-tools/elan/ (last access 18/05/20)

${ }^{2}$ Available at http://multimodal-analysis.com/index.html (last access 18/05/20)

${ }^{3}$ Syllabus Economic English II, Ghent University.

${ }^{4}$ Results were collected in Wordcloud.com

${ }^{5}$ Results collected through menti.com

\section{REFERENCES}

Airey, J. (2016, December). Undergraduate teaching with multiple semiotic resources: Disciplinary affordance vs pedagogical affordance. Unpublished presentation at The $8^{\text {th }}$ International Conference on Multimodality. Multimodal Landscapes: Designing, changing, shaping, University of Cape Town.

Ajayi, L. (2009). English as a second language learners' exploration of multimodal texts in a junior high school. Journal of Adolescent \& Adult Literacy, 52(7), 585-595.

Anderson-Hsieh, J. \& Koehler, K. (1988). The Effect of Foreign Accent and Speaking Rate on Native Speaker Comprehension. Language Learning, 38 (4), 561-613.

Argyle M., Ingham, R., Alkema, F. \& McCallin, M. (1981). The different functions of gaze. In A. Kendon (Ed.), Nonverbal Communication, Interaction and Gesture (pp. 283295). Paris/New York, NY: Mouton.

Bonsignori, V. (2018). Using films and TV series for ESP teaching: A multimodal perspective. System, https://doi.org/10.1016/j.system. 2018.01.005.

Bonsignori, V. (2019). A multimodal analysis of spoken medical English in expert-to-expert interaction in TV programmes. Ibérica, 37, 115-140.

Brazil, D. (1997). The Communicative Value of Intonation in English (2 ${ }^{\text {nd }}$ ed). Cambridge: Cambridge University Press.

Busà, M. G. (2010). Sounding Natural: Improving Oral Presentation Skills. Language Value, 2(1), 51-67.

Campoy Cubillo, M.C. \& Querol Julián, M. (2015). Assessing multimodal listening. In B. Crawford \& I. Fortanet Gómez (Eds.), Multimodal Analysis in Academic Settings: From Research to Teaching (193 -212). London/ New York, NY: Routledge.

Cestero-Mancera, A. (2017). La comunicación no verbal. In A. M. Cestero \& I. Penadés (Eds.), Manual del profesor de ELE (pp. 1051-1122). Alcalá de Henares: Universidad de Alcalá.

Cestero-Mancera, A. (2018). Recursos no verbales en comunicación persuasiva: Imagen, proxémica y paralenguaje. Lengua y Habla, 22, 135-159.

Chang, Y. J. \& Huang H. T. (2015). Exploring TED talks as a pedagogical resource for oral presentations: A corpus-based move analysis. English Teaching \& Learning, 39, 29-62. 
Clarke, J. S., Cornelissen, J. P. \& Healey, M. P. (2019). Actions speak louder than words: how figurative language and gesturing in entrepreneurial pitches influences investment judgments. Academy of Management Journal, 62(2), 335-360.

Coccetta, F. (2018). Developing university students' multimodal communicative competence: Field research into multimodal text studies in English. System, 77, 19-27.

Crawford-Camiciottoli, B. \& Campoy-Cubillo, M.C. (2018) (Eds.) Special Issue: Multimodal Perspectives on English Language Teaching in Higher Education. System, 77.

ELAN (Version 5.2) [Computer software]. 2018, April 04. Nijmegen: Max Planck Institute for Psycholinguistics. Retrieved from https://tla.mpi.nl/tools/tla-tools/elan/

Forey, G., \& Feng, D. (2016). Interpersonal Meaning and Audience Engagement in Academic Presentations: A Multimodal Discourse Analysis Perspective. In K. Hyland and P. Shaw (Eds), The Routledge Handbook of English for Academic Purposes (pp. 416-430). London: Routledge.

Fortanet-Gómez I. \& Bernard-Mechó, E. (Eds). (2019). Multimodal Analysis of Specialized Discourse. Special Issue. Ibérica, 37.

Fuertes-Olivera, P., Velasco-Sacristan, M., Arribas-Baño, A. \& Samaniego-Fernandez, E. (2001). Persuasion and advertising English: Metadiscourse in slogans and headlines. Journal of pragmatics, 33(8), 1291-1307.

Hincks, R. (2005). Measuring Liveliness in Presentation Speech. Proceedings of Interspeech 2005, Lisbon (pp. 765-768).

Hincks, R. (2009). Speaking rate and information content in English lingua franca oral presentations. English for Specific Purposes. Advance online publication. doi:10.1016/j.esp.2009.05.004

Hood, S. \& Forey, G. (2005). Introducing a conference paper: Getting interpersonal with your audience. Journal of English for Academic Purposes, 4(4), 291-306.

Hu, G. \& Liu, Y. (2018). Three minute thesis presentations as an academic genre: across disciplinary study of genre moves. Journal of English for Academic Purposes, 35, 1630.

Huang \& Pearce (2015). Managing the Unknowable: The Effectiveness of Early-stage Investor Gut Feel in Entrepreneural Investment Decisions. The ASQ blog. Retrieved 22 August, 2019 from https://asqblog.com/2016/02/04/huang-and-pearce-2015-managingthe-unknowable-the-effectiveness-of-early-stage-investor-gut-feel-in-entrepreneurialinvestment-decisions/

Hyland, K. (2005). Metadiscourse. London: Continuum.

Iedema (2003). Multimodality, Resemiotization: Extending the Analysis of Discourse as Multi-Semiotic Practice. Visual Communication, 2(1), 29-57.

Jewitt, C. \& Kress, G. (Eds.) (2003). Multimodal Literacy. New York, NY: Peter Lang. 
Jiménez-Muñoz, A. (2019). Beyond language: a multimodal analysis of success in nonnative Business English pitches. Ibérica, 37, 65-86.

Kendon, A. (2004). Gesture. Visible action as utterance. Cambridge: Cambridge University Press.

Kress, G. (2003). Literacy in the New Media Age. London: Routledge.

Kress, G. (2010). Multimodality: A Social Semiotic Approach to Contemporary Communication. London: Routledge.

Lemke, J.L. (1998). Multiplying Meaning: Visual and Verbal Semiotics in Scientific Text. In J. R. Martin \& R. Veel (Eds.), Reading \& Science (pp. 87- 113). London: Routledge.

Levis J. \& Pickering, L. (2004). Teaching intonation in discourse using speech visualization technology. System, 32 (4), 505-524.

Morell, T. (2015). International Conference Paper Presentations: A Multimodal Analysis to Determine Effectiveness. English for Specific Purposes, 37, 137-50.

Morell, T. (2018). Multimodal competence and effective interactive lecturing. System, 77, 19-27.

Norris, S. (2004). Analysing Multimodal Interaction: A Methodological Framework. London \& New York, NY: Continuum.

The New London Group. (1996). A pedagogy of multiliteracies: Designing social futures. Harvard educational review, 66(1), 60-93.

Niebuhr O., Voße, J. \& Brem, A. (2016). What makes a charismatic speaker? A computerbased acoustic-prosodic analysis of Steve Jobs tone of voice. Computers in Human Behaviour, 64, 366-382.

O'Halloran, K., Tan, S. \& Marissa K.L. (2015). Multimodal analysis for critical thinking. Learning, Media and Technology.

O'Halloran, K., Tan, S. \& Smith, B. (2016). Multimodal Approaches to English for Academic Purposes. In K. Hyland \& P. Shaw (Eds.), The Routledge Handbook of English for Academic Purposes (pp. 256-269). London: Routledge.

Palmer-Silveira, J. C. (2015). Multimodality in Business Communication: Body Language as a Visual Aid in Student Presentations. In B. Crawford Camiciottoli \& I. FortanetGómez (Eds.), Multimodal Analysis in Academic Settings: From Research to Teaching (pp. 171-192). London: Routledge.

Poyatos, F. (2002). Nonverbal Communication across Disciplines. Volume II. Paralanguage, Kinesics, Silence, Personal and Environmental Interaction. Amsterdam: John Benjamins.

Querol-Julián, M., \& Fortanet-Gómez, I. (2019). Collaborative teaching and learning of interactive multimodal spoken academic genres for doctoral students. International Journal of English Studies, 19(2), 61-82. 
Rendle-Short, J. (2006). The Academic Presentation: Situated Talk in Action. Aldershot: Ashgate.

Ruiz-Madrid, N. \& Fortanet-Gómez, I. (2016). Exploring research pitches from a multimodal discourse analysis perspective: the role of multimodal ensembles in their generic definition. Oral presentation at the $8^{\text {th }}$ Conference on Multimodality: Multimodal landscapes. Cape Town, South Africa, 2016.

Ruiz-Madrid, N. \& Fortanet-Gómez, I. (2019). A Multimodal Discourse Analysis (MDA) approach for EMI teachers training: The Case of Pedagogical Affordances in the Mechanical Engineering Field. In A.C. Lahuerta- Martínez \& A. Jiménez- Muñoz (Eds.), Empirical Studies in Multilingualism. Analysing Contexts and Outcomes.

Stein, P. (2000). Rethinking resources in the ESL Classroom: multimodal pedagogies in the ESL classroom. TESOL Quaterly, 34(2), 333-336.

Querol-Julián, M. \& Fortanet Gómez, I. (2012). Multimodal evaluation in academic discussion sessions: how do presenters act and react? English for Specific Purposes, 31(4), 271-283.

Valeiras-Jurado, J. \& Ruiz-Madrid, M.N. (2019). Multimodal enactment of characters in conference presentations. Discourse Studies, 21(5), 561-583.

Valeiras-Jurado, J. (2019). Modal coherence in specialised discourse. A case study of persuasive oral presentations in business and academia. Iberica, 37, 87-114. 


\section{APPENDIX: ACTIVITIES INCLUDED IN THE HANDOUT FOR STUDENTS IN ECONOMIC ENGLISH II}

1. Watch these two extracts from two different product pitch presentations. Which of them is more persuasive? Could you rate them from 1-20 taking into account how presenters' make the most of their communication skills.

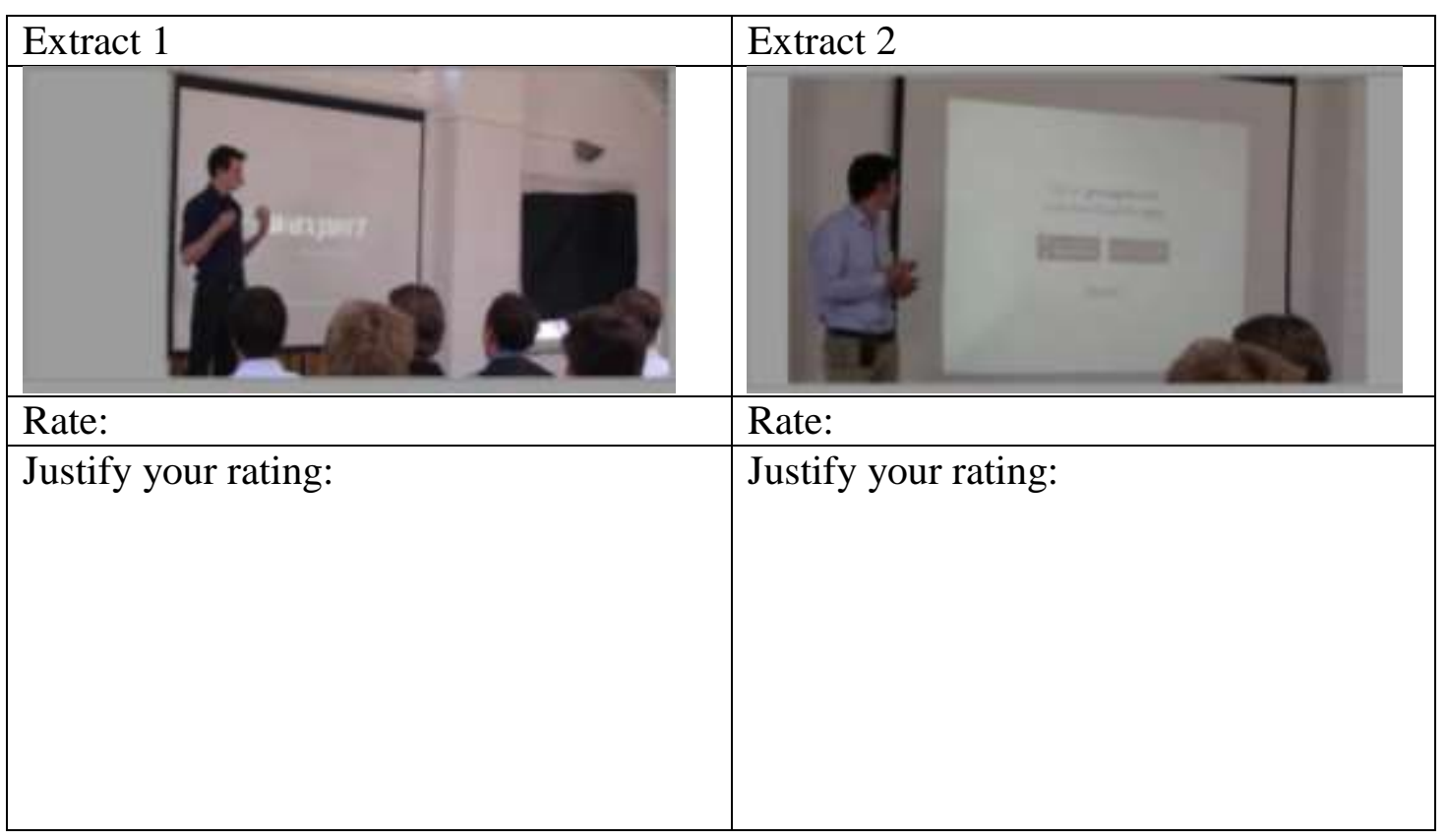

2. Let's watch the videos again and complete the following chart.

\begin{tabular}{|c|c|c|c|c|}
\hline \multirow{2}{*}{$\begin{array}{c}\text { Communicative } \\
\text { resources }\end{array}$} & \multirow[t]{2}{*}{ Used? } & \multicolumn{3}{|c|}{ How much? } \\
\hline & & Little & Average & A lot \\
\hline \multicolumn{5}{|l|}{ Language (words) } \\
\hline \multicolumn{5}{|l|}{ Gesture } \\
\hline \multicolumn{5}{|l|}{ Intonation } \\
\hline Gaze & & & & \\
\hline
\end{tabular}

3. Match each diagram with the correct video and justify your decision.

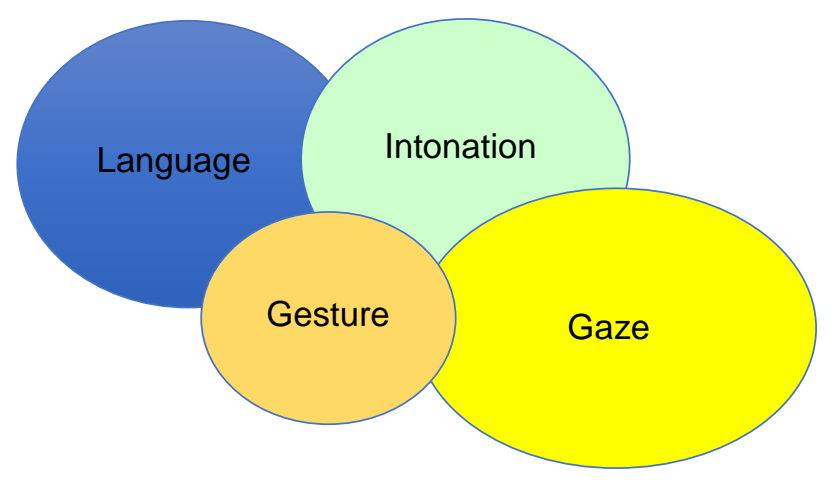

Extract number:

(C) Servicio de Publicaciones. Universidad de Murcia. All rights reserved. IJES, vol. 20(1), 2020, pp. 27-50 


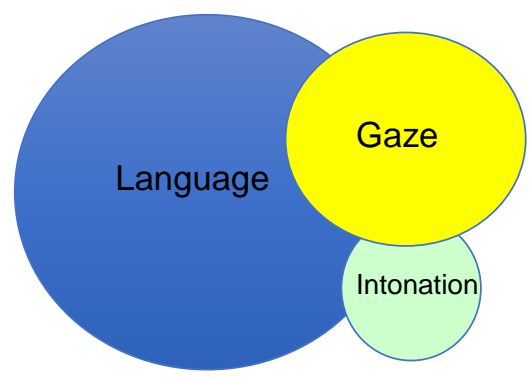

Extract number:

4. Watch this extract now. Do you think the speaker is effective in delivering the take-home message?

\section{YES}

NO

Why?

5. Draw the diagram that represents the communicative resources used by the speaker (look at exercise 3 for a model). 